\title{
Pengaruh Proprioceptive Neuromuscular Facilitation terhadap Kekuatan Fungsi Prehension Cylindrical Grip pada Pasien Stroke Non-Hemoragik
}

\author{
Sabirin Berampu ${ }^{1, *}$, Elsaria Br Sembiring ${ }^{2}$ \\ 1,2Fakultas Keperawatan dan Fisioterapi, Institut Kesehatan Medistra Lubuk Pakam, Lubuk Pakam, 20512, Indonesia \\ ${ }^{1}$ sabirinberampu50@gmail.com*; ${ }^{2}$ elsaria@gmail.com; \\ *corresponding author
}

ARTICLE INFO

Article history

10-08-2021

29-08-2021

11-09-2021

Keywords

PNF

Prehension Cylindrical Grip

Stroke Non-Hemoragik

\section{ABSTRACT}

Stroke is a disease that is most commonly found today, stroke has a high mortality and disability rate. Stroke can cause physical disability in productive age and old age. This study aims to determine the effect of Proprioceptive Neuromuscular Facilitation (PNF) on the strength of the prehension Cylindrical grip function in non-hemorrhagic stroke patients. This research is a quantitative study with a quasiexperimental design, one group pretest and posttest, the samples were taken by purposive sampling, namely non-hemorrhagic stroke patients who visited the physiotherapy poly at Grandmed Lubuk Pakam Hospital. The results showed a p-value of 0.001 which means that there is an effect of PNF on the strength of the prehension Cylindrical grip function in non-hemorrhagic stroke patients.

\section{Pendahuluan}

Stroke merupakan penyakit yang paling banyak ditemukan saat ini, stroke memiliki angka kematian dan kecacatan yang tinggi. Stroke dapat menyebabkan kecacatan fisik pada usia produktif ataupun pada saat usia lanjut [1]. American Heart Association (AHA) melaporkan bahwa stroke menempati rangking ke 4 di dunia setelah penyakit jantung, kanker, dan penyakit pernapasan kronis [2]. Menurut World Health Organization (WHO) terdapat 20 juta orang yang akan meninggal di dunia dikarenakan stroke. Secara global, 15 juta orang terserang stroke setiap tahunnya, satu pertiga meninggal dunia dan sisanya mengalami kecacatan permanen.

Masalah stroke di negara Indonesia menjadi semakin penting karena di Asia menduduki urutan pertama dengan jumlah kasusnya yang semakin meningkat [3]. Hemoragik merupakan jenis yang paling umum menyerang hingga mencapai $80 \%$ stroke ini terjadi karena pembuluh darah menuju ke otak mengalami penyumbatan, sedangkan stroke hemoragik menyerang sekitar $20 \%$, hal ini terjadi ketika pembuluh darah pecah sehingga menyebabkan kebocoran darah disekitar otak [4].

Berdasarkan survey awal yang dilakukan oleh peneliti di Rumah Sakit Grandmed Lubuk Pakam menunjukkan bahwa pasien stroke non-hemoragik yang berkunjung ke poli fisioterapi Rumah Sakit Grandmed cukup tinggi dengan angka prevelansinya yaitu rata-rata yang berkunjung selama satu bulan sekitar 22 orang pada tahun 2020.

Dampak yang timbul pada pasien stroke antara lain gangguan-gangguan fungsi vital otak seperti gangguan koordinasi, gangguan keseimbangan, gangguan kontrol postur, gangguan sensasi, dan gangguan refleks gerak yang akan menurunkan aktivitas fungsional salah satunya adalah kekuatan fungsi prehension Cylindrical grip, karena kekuatan fungsi prehension Cylindrical grip merupakan hal sangat penting dalam menjalankan aktivitas sehari-hari disamping itu, tangan juga merupakan salah satu organ yang paling aktif setelah kaki [5].

Metode terapi yang dapat diberikan untuk mengembalikan kekuatan fungsi prehension Cylindrical grip yaitu terapi proprioceptive neuromuscular facilitation (PNF). PNF salah satu terapi dengan memperbanyak impuls sensoris, berupa penglihatan, pendengaran, proprioseptive, sentuhan, dan tekanan yang dapat menimbulkan umpan balik (feedback) dari suatu gerakan. 
Penguatan impuls sensoris dapat mempercepat palstisitas otak. Pola latihan untuk setiap segmen didasarkan pada gerakan fungsional dan 3 sesi yang dilakukan dalam kegiatan rutin sehari-hari [6].

\section{Metode}

Jenis penelitian ini adalah penelitian kuantitatif dengan menggunakan desain quasi exsperimen one group pretest dan postest, sempel pada penelitian ini adalah pasien stroke nonhemaragik yang berkunjung ke poli Fisioterapi RS Grandmed Lubuk Pakam, dengan teknik pengambilan sampel menggunakanpurposive sampling sebanyak 15 pasien. Pengukuran data dengan menggunakan Hand Dynamometer yang dituliskan dalam lembar observasi pengukuran kekuatan otot genggaman tangan dalam kilogram (CAMRY) terhadap pasien strok nonhemoragik[7], kemudian hasil di analisis menggunakan uji paired t test dengan tingkat kepercayaan $95 \%$ [8].

Etika penelitian, penelitian ini sudah lolos uji etik (mendapat persetujuan etik) dan mendapat sertifikat etik dari Komisi Etik Penelitian Kesehatan Fakultas Keperwatan Universitas Sumatera Utara pada tanggal 01 Juni 2021 dengan nomor 2299/VI/SP/2021.

\section{Hasil dan Diskusi}

Tabel 1. Distribusi Responden Berdasarkan Karakteristik (Umur dan Pendidikan) pada Pasien Stroke Non Hemoragik

\begin{tabular}{lcc}
\hline Karakteristik Responden & $\begin{array}{c}\text { Jumlah Sampel } \\
(\mathbf{n})\end{array}$ & $\begin{array}{c}\text { Presentase } \\
(\mathbf{\%})\end{array}$ \\
\hline Umur & & 40.0 \\
\hline $55-59$ & 6 & 60.0 \\
\hline $60-64$ & 9 & $\mathbf{1 0 0}$ \\
\hline Total & $\mathbf{1 5}$ & \\
\hline Janis Kelamin & & $\mathbf{8 6 . 6}$ \\
\hline Laki-laki & 13 & $\mathbf{1 3 . 4}$ \\
\hline Perempuan & 2 & $\mathbf{1 0 0}$ \\
\hline Total & $\mathbf{1 5}$ & \\
\hline
\end{tabular}

Berdasarkan tabel 1. diketahui jumlah responden berdasarkan rentang umur 55-59 ada sebanyak 6 orang (40.0\%) yang mengalami stroke non hemoragik dan berdasarkan rentang umur 60-64 sebanyak 9 orang (60.0\%). Sedangkan berdasarkan jenis kelamin, ada 13 orang (86.6) berjenis kelamin laki-laki dan 2 orang $(13.4 \%$ berjenis kelamin perempuan yang mengalami stroke hemoragik.

Tabel 2. Distribusi Skor Penilaian Kekuatan Fungsi Prehension CylindricalGrip Sebelum dan Sesudah Pemberian Proprioceptive Neuromuscular Facilitation (PNF) Pada Pasien Stroke Non-Hemoragik

\begin{tabular}{cc|c|c}
\hline $\begin{array}{c}\text { Responden } \\
\text { (n) }\end{array}$ & Sebelum Pemberian PNF & $\begin{array}{c}\text { Sesudah Pemberian } \\
\text { PNF }\end{array}$ & Selisih (Peningkatan) \\
\hline 1 & $24,5 \mathrm{Kg}$ & $25,1 \mathrm{Kg}$ & 0.6 \\
\hline 2 & $34,1 \mathrm{Kg}$ & $35,9 \mathrm{Kg}$ & 1.8 \\
\hline 3 & $37,8 \mathrm{Kg}$ & $40,0 \mathrm{Kg}$ & 2.2 \\
\hline 4 & $27,3 \mathrm{Kg}$ & $27,4 \mathrm{Kg}$ & 0.1 \\
\hline 5 & $33,0 \mathrm{Kg}$ & $35,7 \mathrm{Kg}$ & 2.7 \\
\hline 6 & $46,9 \mathrm{Kg}$ & $48.9 \mathrm{Kg}$ & 2.0 \\
\hline
\end{tabular}




\begin{tabular}{cc|c|c}
\hline 7 & $35,6 \mathrm{Kg}$ & $38,2 \mathrm{Kg}$ & 2.6 \\
\hline 8 & $23,3 \mathrm{Kg}$ & $23,6 \mathrm{Kg}$ & 0.3 \\
\hline 9 & $26,2 \mathrm{Kg}$ & $27,5 \mathrm{Kg}$ & 1.3 \\
\hline 10 & $30,5 \mathrm{Kg}$ & $33,3 \mathrm{Kg}$ & 2.8 \\
\hline 11 & $38,4 \mathrm{Kg}$ & $42,2 \mathrm{Kg}$ & 3.8 \\
\hline 12 & $45,0 \mathrm{Kg}$ & $48,1 \mathrm{Kg}$ & 3.1 \\
\hline 13 & $30,1 \mathrm{Kg}$ & $32,8 \mathrm{Kg}$ & 2.7 \\
\hline 14 & $45,0 \mathrm{Kg}$ & $48,1 \mathrm{Kg}$ & 3,1 \\
\hline 15 & $30,1 \mathrm{Kg}$ & $32,8 \mathrm{Kg}$ & 2,7 \\
\hline $\begin{array}{c}\text { Total rata- } \\
\text { rata }\end{array}$ & $\mathbf{3 2 . 9 9}$ & $\mathbf{3 5 . 5 3}$ & $\mathbf{1 . 7 3}$ \\
\hline
\end{tabular}

Dari tabel 2. Diketahui bahwa nilai kekuatan fungsi prehension pasien stroke hemoragik sebelum intervensi antara 23,3 sampai 46,9 dengan rata-rata nilai 32,99 dan setelah intervensi antara 23.6 sampai 48,9 dengan nilai rata-rata 35,53 sedangkan selisih atau peningkatan skor sebelum dan sesudah intervensi antara 0,1 sampai 3,8 dengan rata-rata 1,73.

Tabel 3. Hasil Uji Statistik Kekuatan Fungsi Prehension Cylindrical Grip Sebelum dan Sesudah Pemberian Proprioceptive Neuromuscular Facilitation (PNF)

Pada Pasien Stroke Non-Hemoragik.

\begin{tabular}{cccccc}
\hline $\begin{array}{c}\text { Kekuatan Fungsi } \\
\text { Prehension }\end{array}$ & n & Mean & $\begin{array}{c}\text { Std } \\
\text { Deviation }\end{array}$ & t & $\begin{array}{c}\text { Sig.(2- } \\
\text { tailed) }\end{array}$ \\
\hline Sebelum PNF & 15 & 32.99 & 7.130 & & \\
\cline { 1 - 3 } Sesudah PNF & 15 & 35.53 & 8.443 & -3.731 & 0.002 \\
\hline
\end{tabular}

Hasil uji statistik dengan menggunakan uji paired sample t test didapatkan rata-rata nilai sebelum PNF 32.99 dan setelah diberikan PNF 35.53 dengan nilai $p$-value $=0.002$ dimana nila p-value lebih kecil dari alpha 0.05 yang artinya ada pengaruh yang signifikan sebelum dan sesudah PNF pada pasien stroke non-hemoragik di Rumah Sakit Grandmed Lubuk pakam.

Penelitian ini dilakukan selama 4 minggu dengan 8 kali pertemuan, Responden melakukan 30 menit diagonal ekstermitas atas yang terbagi menjadi 3 sesi dan setiap sesi diberikan istirahat selama 5 menit, kemudian dilanjutkan dengan latihan mengenggam untuk mengetahui fungsi prehension Cylindrical grip yang diukur dengan menggunakan alat ukur hand dynamometer sebelum dan sesudah intervensi diberikan.

Hasil penelitian pada tabel 1. menunjukkan bahwa berdasarkan karakteristik umur responden yang mengalami strok non-hemoragik mulai dari umur 55 - 64 tahun dengan mayoritas rentang umur 60-64 tahun sebanyak 9 orang $(60.0 \%)$. Menurut penelitian Wardhani dan Martini (2014) menyatakan bahwa stroke pada umumnya dapat terjadi pada semua kelompok umur, tetapi tiga perempat dari kejadian stroke terjadi pada orang yang sudah berumur 55 tahun atau lebih (lansia) dan berakibat disabilitas dan kecacatan. Pada lansia terjadi penurunan struktur dan fungsi organ tubuh sehingga lansia lebih rentan terhadap berbagai penyakit baik degenerative maupun infeksi. Umur merupakan salah satu faktor resiko stroke. Semakin bertambahnya usia seseorang maka resiko terkena stroke semakin meningkat. Hal ini disebabkan karena adanya kelemahan fungsi tubuh secara menyeluruh terutama fleksibilitas pembuluh darah [9].

Berdasarkan hasil penelitian pada tabel 1. juga menunjukkan bahwa jumlah sampel 
jenis kelamin laki-laki adalah sebanyak 13 orang (86.6\%) dan perempuan 2 orang (13.4\%). Hasil penelitian ini sejalan dengan penelitian Wahyuddin (2018) bahwa kejadian stroke lebih banyak pada laki-laki dibandingkan wanita. Kondisi ini diduga berhubungan dengan lifestyle dan berkaitan dengan faktor yang lain seperti merokok, konsumsi alkohol dan dislidemia.

Berdasarkan hasil penelitian pada tabel 3. sebelum dilakukan pemberian Proprioceptive Neuromuscular Facilitation (PNF) di ketahui nilai rata-rata kekuatan fungsi Prehension Cylindrical Grip sebesar 32.99 dengan SD=7.130 Sedangkan setelah pemberian Proprioceptive Neuromuscular Facilitation (PNF) di ketahui nilai rata-rata kekuatan fungsi Prehension Cylindrical Grip sebesar 35.53 dengan $\mathrm{SD}=8.443$. Hasil uji statistik diperoleh nilai $\mathrm{p}$-value $0.002<0.05$, maka dapat disimpulkan ada pengaruh sebelum dan sesudah pemberian Proprioceptive Neuromuscular Facilitation (PNF) terhadap kekuatan fungsi Prehension Cylindrical Grip pada pasien stroke non-hemoragik.

Hasil penelitian ini sesuai dengan penelitian yang dilakukan oleh Wahyuddin, (2018) tentang Pengaruh Proprioceptive Neuromuscular Facilitation (PNF) terhadap kekuatan fungsi Prehension cylindrical grip pada post stroke hemoragik dan non-hemoragik yaitu terapi latihan metode PNF yang diberikan pada pasien post stroke dengan frekuensi dua sampai tiga kali setiap minggu pada pasien post stroke non-hemoragik fase penyembuhan dapat meningkatkan kekuatan fungsi prehension cylindrical grip [10].

Stroke merupakan suatu kondisi yang dapat terjadi ketika aliran darah ke otak tiba-tiba mengalami gangguan, karena kurangnya aliran darah dan oksigen ke dalam jaringan otak, strok non-hemoragik disebabkan karena penumpukkan kolestrol pada dinding pembuluh darah atau karena tersumbatnya pembuluh darah ke otak karena adanya bekuan darah. Hal ini dapat menyebabkan pasien tidak mampu melakukan aktivitas sehari-hari karena tubuh tidak dapat berfungsi dengan baik, sehingga pasien ketergantungan kepada keluarga ataupun obat yang diminumnya [11].

Strok dapat mempengaruhi fungsi tubuh tidak dapat aktif secara sempurna, terutama pada bagian tangan, dalam kehidupan sehari-hari fungsi tangan sangat penting karena tangan merupakan bagian tubuh yang paling aktif untuk melakukan aktivitas, maka jika pasien mengalami strok akan mengganggu dan tidak dapat memenuhi kebutuhan sendiri. Tangan juga merupakan salah satu panca indra yang berguna secara khusus, dalam penelitian ini peneliti menggunakan Cylindrical grip untuk terapi karena Cylindrical grip merupakan salah satu terapi yang dapat digunakan untuk merangsang atau mengatur kekuatan otot. Selian itu terapi yang digunakan adalah dengan tehnik PNF karena PNF merupakan terapi yang sangat praktis dan mudah diterapkan. Metode terapi ini dikembangkan oleh Herman Kabath dan miss Margareth Knot pada Khabat Kaiser Institute tahun 1946 dan tahun 1951 dengan terbitnya buku "Proprioseptive Neuromuscular Facilitation (PNF)" [12], dan dari hasil penelitian membuktika bahwa ada pengaruh secara significant antara sebelum dan sesudah intervensi diberikan hal ini dikarenakan para responden dapat mengikuti terapi dengan rutin dan mau mengikuti instruksi dengan baik selama penelitian berlangsung, selainitu dibuktikan dengan hasil uji statistic di peroleh nilai selisi antara sebelum dan sesudah intervensi rata-rata 1.73 sesuai dengan tabel. 2 , dengan nilai p-value 0.002 lebih kecil dari 0.005 .

Angka kejadian stroke yang semakin meningkat setiap tahunya, maka perlu menjadi perhatian yang khusus dan serius bagi pemerintah ataupun pihak fasilitas kesehatan yang berperan langsung khususnya rumah sakit. Fisioterapi memiliki peranan yang sangat penting untuk membantu proses pemulihan karena kasus stroke tidak cukup hanya ditangani oleh medis melainkan perlu andanya terapi atau latihan untuk mengembalikan fungsi kekuatan otot terutama pasien yang mengalami stroke non-hemoragik.

\section{Kesimpulan}

Hasil penelitian menunjukkan ada pengaruh yang signifikan Sebelum dan Sesudah Pemberian Proprioceptive Neuromuscular Facilitation (PNF) Pada Pasien Stroke Non-Hemoragik hal ini dapat dibuktikan secara statistik dengan nilai $\mathrm{p}$-value $0.002<0.05$. 


\section{Ucapan Terima Kasih}

Terima kasih kepada Kementerian Pendidikan Kebudayaan, Riset dan Teknologi dankepada Lembaga Layanan Pendidikan Tinggi Wilayah I (LLDIKTI) serta Rumah Sakit Grandmed Lubuk Pakam, Kabupaten Deli Serdang. Dengan adanya bantuan dari semua pihak,penelitian ini dapat berlangsung dengan baik semoga hasil penelitian ini dapat bermanfaat untuk masyarakat khususnya pasien yang mengalami stroke non-hemoragik.

\section{Referensi}

[1] Mutiarasari, D. Medika Tadulako. Jurnal Ilmiah Kedokteran, Vol. 1 No. 2. Jurnal Ilmiah Kedokteran, 1 (2), 36-44. 2019.

[2] Ramdani, M. L. Karakteristik dan Periode Kekambuhan Stroke pada Pasien dengan Stroke Berulang di Rumah Sakit Margono Soekardjo Purwokerto Kabupaten Banyumas. Jurnal Keperawatan Muhammadiyah, 3(1), 1-15. https://doi.org/10.30651/jkm.v3i1.1586. 2018.

[3] Graha. A. and Priyonoadi.B. Terapi Masase Frirage. Yogyakarta: FIK UNY. 2012.

[4] Duta Daniel, dkk. The Pnf (Proprioceptive Neuromuscular Facilitation) Stretching Technique-A Brief Review Journal series Physical Education And Sport. Romania Ovidius University Science, Movement And Health. 2013.

[5] Ghodey, R. P. Added Effect of Graded Motor Imagery on Upper Limb Function in Stroke Patients. International Journal of Science and Research (IJSR), 7(3), 1096-1103. 2018.

[6] Guiu-Tula, F. X., Cabanas-Valdés, R., Sitjà-Rabert, M., Urrútia, G., \& Gómara-Toldrà, N. The Efficacy of the proprioceptive neuromuscular facilitation $(P N F)$ approach in stroke rehabilitation to improve basic activities of daily living and quality of life: A systematic review and meta-analysis protocol. BMJ Open, 7(12), 1-5. https://doi.org/10.1136/bmjopen2017-016739. 2017.

[7] Camry, NC. Electronic Hand Dynamometer Instruction manual. Zhongshan Camry Electronic Co. Ltd., Zhongshan, China. 2014.

[8] Sugiyono, Metode Penelitian Pendidikan. Bandung; Alfabet. 2014.

[9] Whardani, N. \& Martini, S., Faktor yang Berhubungan dengan Pengetahuan Tentang Stroke Pada Pekerja Institusi Pendidikan Tinggi. Jurnal Epidemiologi, 2(1):13-23. 2014.

[10] Wahyuddin \& Arif W. Pengaruh PNF terhadap kekuatan fungsi Prehension cylindrical grip pada post stroke hemoragik dan non-hemoragik. Jurnal Ilmiah Fisioterapi Esa Unggul eISSN : 2528-3235, p-ISSN : 1858-4047. 2018.

[11] Prosper, O. U., Chuba, O. G., C, I. S., E, I. Y., Afam, E. V, J, N. M., \& Onuwa, U. J. (2017). Effects of Proprioceptive Neuromuscular Facilitation and Balance Training on Activities of Daily Living (ADL) of Stroke Survivors with and without Cognitive Impairment. International Journal of Stroke Research, 2017(1), 1-9. https://doi.org/10.5923/j. stroke.20170501.01. 2017.

[12] Akinwande OA, Adegbesan OA, Babalola JF, Atowoju AA, Mbada CE. Hand grip strength in elderly patients with chronic illnesses: A case control study. Journal of health science 5 (5):81-88. http://article.sapub.org/10.5923.j.health.20150505.01. 2015. 